\section{More behaviourism}

About Behaviourism. By B. F. Skinner. Pp. $256+$ viii. (Jonathan Cape: London, February 1975.) £3.50.

PROFFSSOR Skinner is unrepentant. Assailed by the liberal and radical establishment as a reactionary witchdoctor intent on subjecting human freedom to blind conditioning, attacked by the new school of linguistics and cognitive epistemology as an ignorant primitivist, Skinner not only maintains his position but makes it more dogmatic.

The concept of mind is an obscurantist 'invention' largely attributable to Plato. The only distinctive characteristic of verbal behaviour is the fact that "it is reinforced by its effects on people". Dreams, fantasies, déjà-vu are merely re-cognitions of "what we have once cognised", in some of which certain controlling features of self-knowledge are defective. Human thought equals human behaviour: sum ergo cogito. Faith is just "a matter of the strength of behaviour resulting from contingencies which have not been analysed". Mentalist explanations "explain nothing". Behaviourism, on the contrary, puts us in a position to alter and improve the condition of mankind if only we will apply its commanding insights into the role of the environment and into the agency of such cardinal notions as reinforcement and operant behaviour.

Neither the strategy of the argument nor the tone of mildly outraged common sense are at all new. If there is innovation it can be found in the tactics of Professor Skinner's case, particularly in his increasing resort to a Darwinian idiom. In an important sense, we are told, "all behaviour is inherited, since the organism that behaves is the product of natural selection. Operant conditioning is as much a part of the genetic endowment as digestion or gestation". The origin of behaviour "is not unlike the origin of species. New combinations of stimuli appear in new settings, and responses which describe them may never have been made by the speaker before, or heard or read by him in the speech of others. There are many behavioural processes generating 'mutations', which are then subject to the selective action of contingencies of reinforcement."

What is going on here is plain. Darwinian and post-Darwinian terminology is being used in an attempt to refute the drastic onslaught on behaviourism by Chomsky (whom Skinner, either in coyness or contempt refuses even to mention by name). Dismissing the entire basis of innateness in transformational-generative theories of speech and consciousness, Skinner declares that "grammatical behaviour" has always been shaped by the reinforcing practices of given verbal communities in which some behaviours were more cffective, more provocative of are not generated by imaginary 'deep structures' but, like all other human proceedings, by "the joint action of past reinforcements and current settings".

As one follows this controversy, a sense of exasperation mounts. It is so utterly clear that both sides simplify, distort, and finally trivialise reality. Skinner is perfectly right when he observes that Chomsky's model is full of logical and evidential loopholes, that it absurdly neglects environmentalhistorical factors, that it is dogmatic and even 'mystical' in its presupposition of deep structures and mental 'presettings'. Chomsky, on the other hand, has shown beyond doubt that a stimulus-response paradigm along Skinnerian lines is totally inadequate to explain either the process of language acquisition and innovation or the prevalence (or what looks like the prevalence) of rule-governed similarities across the field of all known grammars. But, surely, there is no need here of a doctrinal either/or. The evolution of human speech and cognition is neither Skinnerian nor Chomskyan, but represents a constant dynamic reciprocity between universal neurophysiological features on the one hand and the contingencies of the environment on the other, between predisposition and reinforcement, between mimesis and discovery. Indeed, using a Darwinian analogue, one would want to argue, with far more attention to the facts than is shown by either behaviourism useful response, than others. Sentences

or transformational-generative linguistics, that man's language capacity is uniquely adaptive. Through words he constructs worlds more bearable than that of his organic surrounding. Through the future tense he does something to circumvent the totality of biological death.

Skinner's contributions to experimental psychology, to learning theory and the understanding of conditioning and reinforcements stand secure. It is a pity that they should be overshadowed by an embattled dogmatism the political add philosophical consequences of which are not necessarily sinister, but are certainly naive. George Steiner

Animal Nature and Human Nature. By W. H. Thorpe. Pp. xviii +435 . (Methuen: London, January 1975.) $£ 7.20$.

IT is of interest to compare Animal Nature and Human Nature with Skinner's new book, About Behaviourism. Although Thorpe thinks human behaviour cannot be explained solely by genetic and experiental factors whereas Skinner adopts a strictly deterministic position, the similarities between the two books are more striking than the differences. Both authors believe that if human behaviour were so determined, our freedom of will would be constrained; both rely heavily on assertion and on appeals to authority rather than on argument, though naturally the quoted authorities differ; both dogmatically reject computer programs as possible models of the mind without examining any such programs; both put forward Utopian views of man's future without taking the trouble to think out what sort of Utopia they want; neither gives evidence of having read, let alone

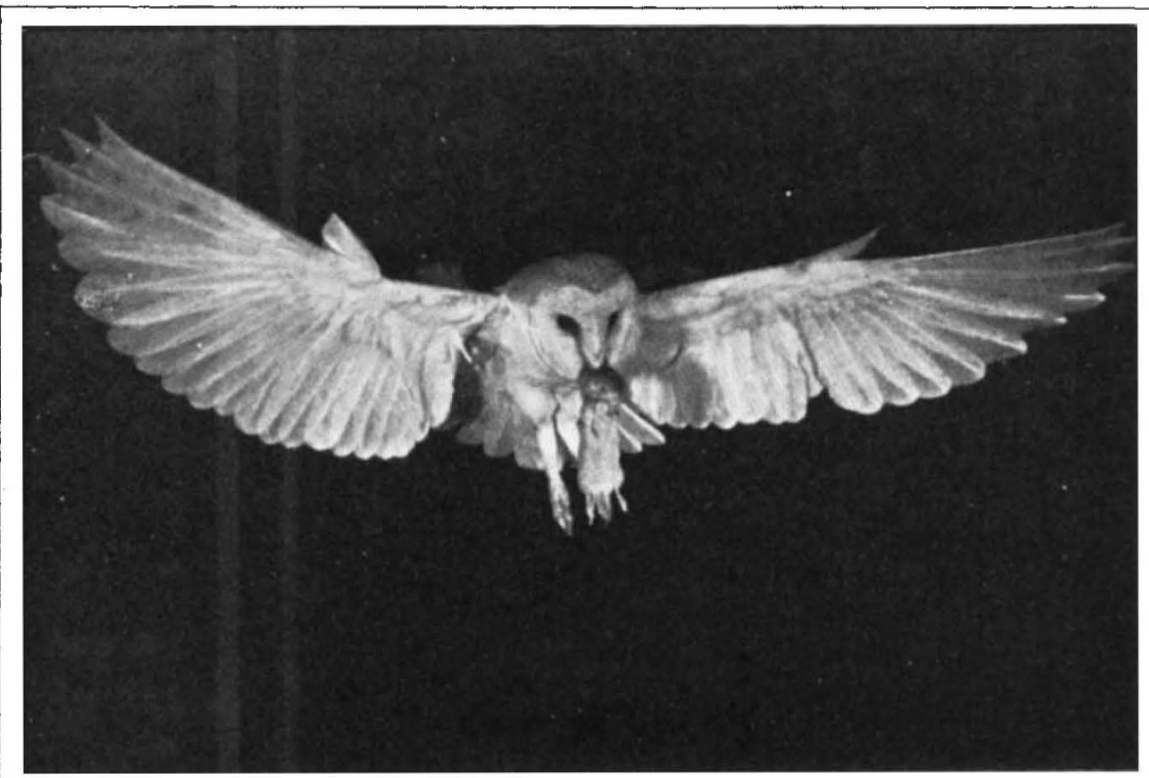

All slots open, flaps down, and undercarriage lowered, the barn owl approaches home. From Natural History Photography. Edited by D. M. Turner Ettlinger. Pp. xxvii + 395. (Academic: London, 1974.) £8.80; \$23.25. 
understood, any arguments against their own position; finally, nothing of any scientific or ethical consequence follows from the contrasting stances taken up by each author.

Thorpe's book is perhaps the less bad, if only because, unlike Skinner, he gives some interesting examples of the results of his own science. He culls from recent work in ethology instances of fixed action patterns, animal communication systems, and social organisation in mammals. Such phenomena have an inherent fascination: like most ethologists Thorpe is at his best when describing such behaviour and speculating on its survival value. $\mathrm{He}$ is less good at specifying the mechanisms that mediate it. On many issues, such as nature against nurture, he takes a sensible position - he rightly castigates Hebb for his declaration that it is absurd to ask how far a given piece of behaviour is innate, how far it is learned. Thorpe's chapter on perception is weak: he still thinks of perception in terms of pattern recognition and fails to get across the idea that perception must involve forming rerpesentations of the outside world which can be manipulated in ways that serve to guide the organism around. In this chapter, his accounts of much experimental work are somewhat cursory and inaccurate.

In arguing for an antireductionist, emergent view of mind he fields the standard team of obscurantists: Koestler, Polyani, McKay, Eccles, Dobzhansky, Weiss, Hardy and Teilhard de Chardin. His eleven is made up by enrolling two new players, Chomsky and Popper, and by using a theologian (Hick) as long-stop. With the exception of the two beginners, these players proceed to throw around terms like 'emergent', 'consciousness', 'determined', 'free-will', 'wholes-greater-thanthe-sum-of-their-parts', and so on. We are treated to such sentences as "the ego's view of the physical world will thus be mediated by a mechanism working just like television". On page 341 there is even a diagram showing (with a dotted line) how "mental space" intersects three-dimensional physical space. The players have such an enjoyable time tossing the ball to one another and cheering each other on, that they seem quite to have forgotten to notice the opposition. Nevertheless, they make their opponents' task very difficult, since the game is played with no rules or definitions; but it may be worth examining a few of the many non sequiturs.

Thorpe accepts McKay's proof that behaviour is indeterminate: in attempting to predict our own behaviour, we change our internal state and, short of an infinite regress, we cannot take such changes into account in making our predictions. The premise is correct but the conclusion does not follow: do we regard computers as being indeterminate because no program could completely predict what it will do? Again, it is correctly stated, following Popper, that at each level of explanation it is necessary to evolve concepts appropriate to that level. To explain and predict the behaviour of a gas we need concepts like pressure, appropriate to collections of molecules not to individual molecules, and to explain the workings of a computer program wc need concepts such as 'conditional jump', 'recursion', and 'iterative loop' that cannot be applied to transistors. If this is all Thorpe means by "emergent qualities", then we can readily concede that a system with the highly unusual organisation of the brain is likely to have emergent qualities, without committing ourselves to the belief that there is some special sense in which human behaviour is 'undetermined' and without supposing that there is a twoway interaction between consciousness and matter. Thorpe also uses the "gawping at Nature" argument: we do not understand why some bird songs and displays should be as elaborate as they are, but present ignorance is no reason for assuming that no scientific explanation will in future be found. It is particularly curious that Thorpe should use this argument since else- where he points out that some highly complex behaviour once thought to indicate the presence of a life-force or creator can nowadays be explaincd in mechanistic terms.

The asertion that "Sir Karl Popper comes down with all the weight of his great learning and experience heavily on the side of dualism" surely does not exempt Thorpe from considering the difficulties inherent in this position. The polemical parts of the book are written in the vaguest of terms. Thorpe dismisses computers as models of the mind without discussing any work in artificial intelligence, yet telepathy and clairvoyance are uncritically accepted on the strength of the questionable work of such experimenters as Soal and of Koestler's collection of unlikely coincidences. The distinguishing characteristic of the human race is said to be religion.

The book is based on a series of Gifford lectures delivered at $\mathrm{St}$ Andrews: such lecturers are instructed, under Lord Gifford's will, to deal with natural religion "as a strictly natural science, the greatest of all sciences"; but this instruction is usually interpreted by the lecturers themselves to mean they should treat of their own subject matter in religious terms. The present book is a fine example of the Gifford Lectureship Syndrome.

N. S. Sutherland

\section{Factors leading to schizophrenia}

Genetics, Environment and Psychopathology. (North Holland Research Series on Early Detection and Prevention of Behaviour Disorders, vol. 1.) Edited by S. A. Mednick, F. Schulsinger, J. Higgins and B. Bell. Pp. xiv +346 . (North Holland: Amsterdam and Oxford; American Elsevier: New York, 1974.) $£ 9.25$.

IN 1962 the Psykologisk Institut in Copenhagen began a research project aimed at the early detection and prevention of mental illness. This book brings together a number of studies conducted at the Institute over the last 10 years. Many have contributed to the research, and 20 authors from the USA, Denmark, Iran and the UK, write in this volume.

The authors were dissatisfied with research on people already schizophrenic and so they conducted prospective studies of people at risk. They used children of schizophrenic parents and selected control groups. Unexpectedly, they found that perinatal factors influenced later outcome and so they established a new study in greater detail, using babies born in Copenhagen between 1959 and 1961. They linked that with Professor Preben Plum's detailed peri- natal study of 9,006 deliveries during that period.

The methods that were used are described fully. They were of a high standard and good contact was maintained with family doctors and hospitals. There is a full list of references which will be valuable to others studying in this field, and there is an index.

The book represents a considerable advance towards the unravelling of genetic and environmental factors in the origins of schizophrenia. Electrodermal responses were used in several of the studies, and some of the authors characterise schizophrenia as a learned pattern of avoidance responses. As treatment seems to offer little, attention has been concentrated on methods of prevention of the development of schizophrenia in 'high risk' children. The authors have made excellent use of the Danish Register of Adopted Children. Schizophrenia is only one of the mental illnesses studied, and the effect on being reared by a schizophrenic mother is tentatively separated from inherited factors.

This volume is good value for money for all research workers in this field and will be of great interest to all field workers.

R. Mac Keith 